\title{
Innovative Method to Perform Micro PCNL in Centres without ESWL and Without Standard Equipment for Micro PCNL
}

\author{
Dr. Siddhant Kumar*, Dr. Vipin Kumar, Dr. Sajad Ahmad Para, Dr. M.K. Maheshwari
}

Dept. of General Surgery, Subharti Medical College, Delhi Meerut Bypass Road, Meerut, UP - 250005, India

DOI: $10.36347 /$ sasjs.2020.v06i03.004

| Received: 29.02.2020 | Accepted: 07.03.2020 | Published: 13.03.2020

*Corresponding author: Dr. Siddhant Kumar

Abstract

Original Research Article

Introduction: Percutaneous nephrolithotomy (PCNL) has undergone significant changes with time to improve efficacy, decrease size of incision and thereby reducing morbidity. Newer minimally-invasive modalities of PCNL such as mini-PCNL, ultra-mini PCNL, and micro-PCNL have evolved with advancement in optics and technology. We here in describe a technique with which minimally invasive PCNL can be performed in centres without ESWL and without standardised equipment for micro-PCNL (<10Fr). Method: Micro PCNL can be performed with the help of a rigid uretroscope (4.5 Fr Wolf URS) Results: Using Micro PCNL by decreasing the tract size, the risk of haemorrhage and organ injury can be decreased while maintaining adequate stone clearance.

Keywords: Innovative Micro Pcnl nephrolithotomy uretroscope.

Copyright @ 2020: This is an open-access article distributed under the terms of the Creative Commons Attribution license which permits unrestricted use, distribution, and reproduction in any medium for non-commercial use (NonCommercial, or CC-BY-NC) provided the original author and source are credited.

\section{INTRODUCTION}

Percutaneous nephrolithotomy (PCNL) was described 40 years ago, and since has continued to undergo innovation and minimization. These advancements are focussed towards delivering greater stone clearance, while minimising morbidity, procedure time and length of hospital stay

Tract creation and dilation in standard PCNL risks haemorrhage and organ injury, hence reduction in the tract size by miniaturisation of equipment/instrument size with the introduction of laser technology and improved optic systems has been attempted.

According to largest instrument size employed, ultra-mini PCNL is classified when the incision is between 11-14 Fr and micro PCNL when it is $<10$ Fr.

\section{METHOD}

\section{Surgical Technique}

\section{Micro - PCNL}

The procedure is performed under general anesthesia/spinal anaesthesia. Initially, the patient is placed in lithotomy position and a 6 Fr ureteric catheter is positioned in the pelvi-calyceal system under cystoscopic and fluoroscopic guidance.
A 14/16 Fr Foley's catheter was placed for bladder drainage and the patient was turned prone. The initial puncture was obtained using USG/fluoroscopic guidance by a standard bull's eye technique over the desired calyx and a guidewire was introduced (Fig. 1).

Tract dilation was done with the help Alken Metal dilator (9 Fr) up to the desired calyx. (Fig. 2) Ureteroscope (4.5 Fr - Wolf) introduced through Alken Metal dilator (Fig. 3).

The stone was fragmented completely with holmium laser (Fig. 4) with a 365 micron end-firing laser fiber at power setting ranging between 12 and 50 $\mathrm{W}(0.8-1.5$ Joules, $15-40 \mathrm{~Hz})$. Once the stone was cleared, the clearance was confirmed with direct nephroscopy and fluoroscopy. A DJ stent was placed or the ureteric catheter left overnight for drainage. Nephrostomy tube was not routinely placed.

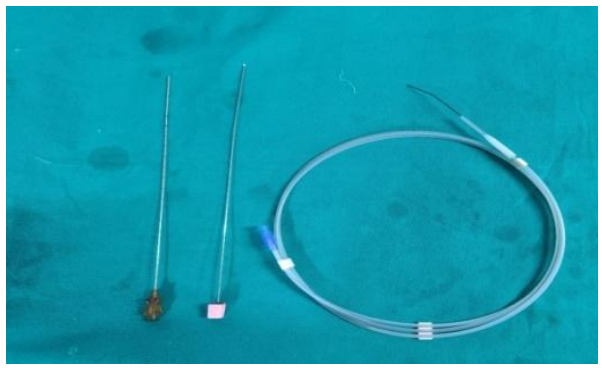

Fig-1: Cook Initial puncture needle and guide wire (terumo wire $-0.035 ")$ 


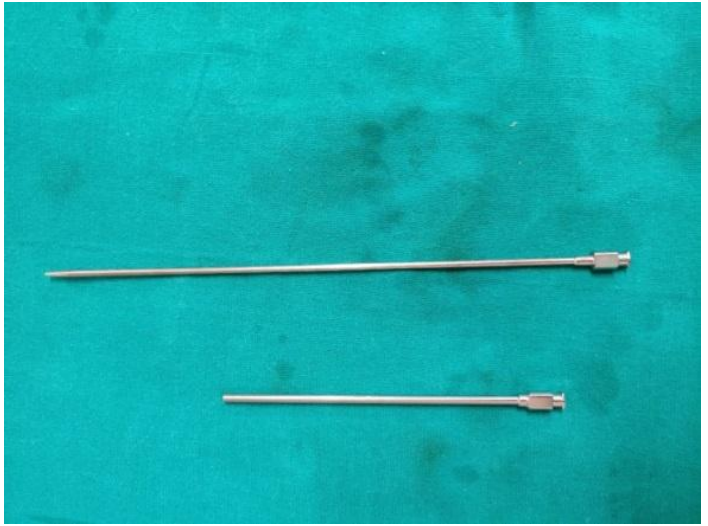

Fig-2: Alken Metal dilator (9 Fr)

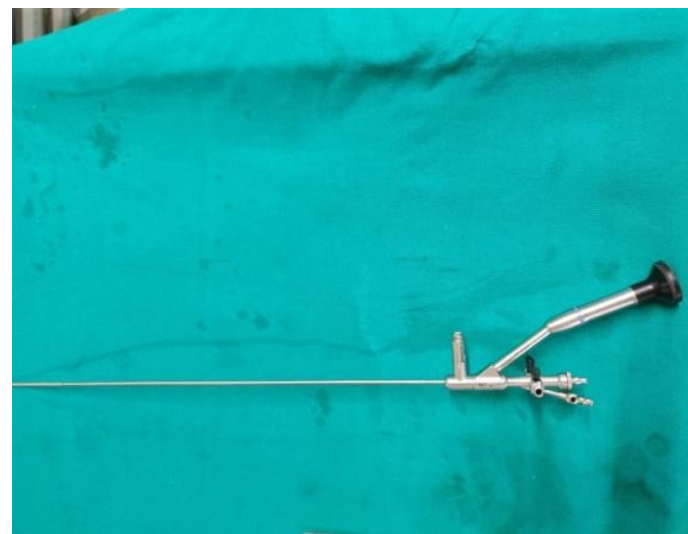

Fig-3: Ureteroscope (4.5 Fr- Wolf)

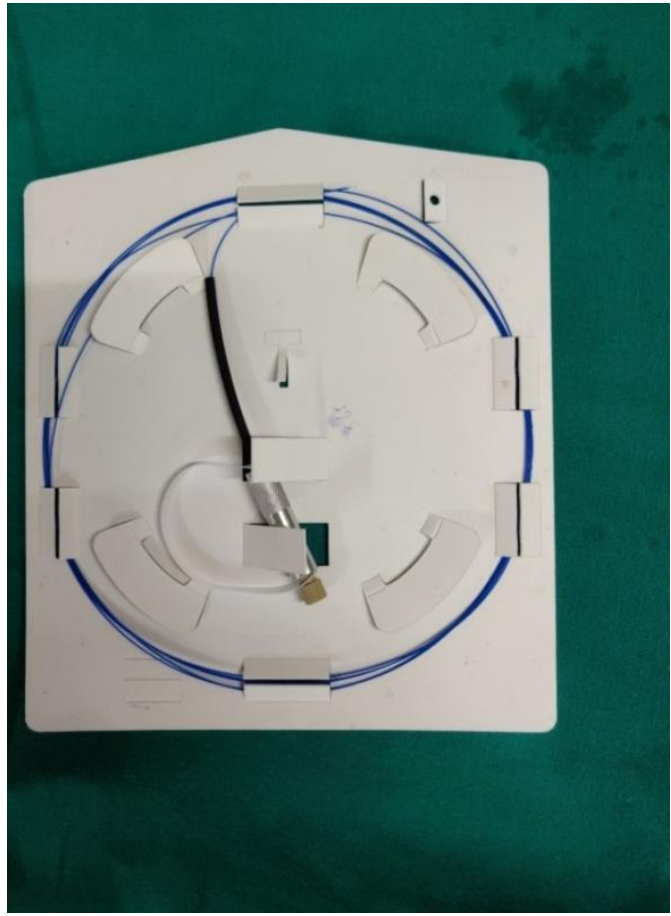

Fig-4: Holium Laser (365 microns)

\section{DISCUSSION}

The best therapeutic approach for $1-2 \mathrm{~cm}$ renal stones is still under debate. The European Association of Urology guidelines recommend different treatment strategies for renal calculi in different sizes and locations [3]. While endourological procedures such as
PCNL and retrograde intrarenal surgery (RIRS) are accepted as the first-line treatment modality for stones larger than $2 \mathrm{~cm}$ in diameter, SWL is preferred for smaller renal stones. The objectives of high stone clearance, minimal invasiveness, short treatment time, and reduced costs are of great interest in determining the treatment strategy, especially in populations with limited resources.

PCNL is a better treatment modality than SWL in terms of stone clearance and is not affected by anatomical factors. Albala et al. compared outcomes of PNL and SWL in lower calyx stones. The stone-free rate was reported to be $90 \%$ and $59 \%$, respectively [1]. Similarly in another randomized study by Lingeman et al., comparing SWL and PNL for renal calculi $\leq 3 \mathrm{~cm}$, success rates of PNL for lower calyx stones were significantly higher than with SWL [2].

RIRS with the new generation flexible ureterorenoscopes has emerged as a preferred management option for low-volume renal stones in recent years. However, like SWL, the success of f-URS significantly decreases in cases of unfavorable anatomical factors such as a long, lower calyx infundibulum and acute infundibulopelvic angle $\left(<30^{\circ}\right)$ [3]. The success of f-URS is reported to be higher than for SWL but lower than for PCNL [4, 5]. Regardless of the high stone-free rate, PNL has a statistically higher complication rate than RIRS and SWL for medium sized renal stones $(13.19 \%, 5.26 \%$, and $3.16 \%$, respectively; $\mathrm{P}<0.05$ ) [11]. A study comparing UMP with f-URS found no significant differences in operating times (UMP vs. f-URS: $121 / 102 \mathrm{~min}$ ), hospital length of stay (2.3/2.0 days), SFR (84/87\%), and complications $(7 / 7 \%)$. However, the costs for disposable materials and endoscopes were less with UMP than with f-URS [6].

With the advent of newer technology in optics and lasers, plenty of options in the form of mini PCNL (MIP) [7], UMP [8] and micro PCNL [9] have come up. These have achieved good success rates with lower complication rates as compared to conventional PCNL owing to the size of the tract. Mini-PCNL performed through 20 Fr tract was introduced by Jackman et al.[10] and Helal et al.[11] especially for pediatric cases. In Mini-PCNL the stone fragments are washed out by the turbulence of irrigation fluid, the so-called "eddy-current" effect, and the intra-pelvic pressure is expected to remain low due to open-ended Amplatz sheath.

\section{Comparing Micro-PCNL with RIRS}

The stone clearance rate achieved with RIRS ranges from $84 \%$ to $97 \%$ and it has a low risk of complication with small renal stones $[16,17]$. However, in lower calyceal calculi, the stone clearance rate falls, especially if the lower calyceal infundibulum is narrow with an acute angle. The drawbacks of RIRS include the 
need do a staged procedure if ureter could not be dilated, higher cost, need for multiple sessions to improve stone clearance, risk of ureteric damage and higher requirement for ureteric stenting[18,19]. RIRS has favourable post-operative pain scores and a lower hemoglobin drop. Microperc is associated with a better surgeon comfort and lower need for double-J stenting. Thus, microperc could be considered as a safe and effective alternative to RIRS in the management of small renal calculi. The advantage of microperc will be especially evident in lower calyceal calculi.

Microperc can be potentially advantageous in the pediatric age group [20]. RIRS is associated with a small but significant risk of injury to the delicate pediatric ureters [21]. In a series of 170 children undergoing flexible ureteroscopy, $57 \%$ required passive dilatation of the ureter for 1-2 weeks before ureteroscope could be inserted into the ureter [22]. In comparison, it will be possible to perform a microperc in the first setting in nearly all children. Flexible ureteroscopes have a short life span and high cost of maintenance. Cost comparison between microperc and RIRS has not been performed so far. However, in view of the short and straight telescope without any deflection mechanism, microperc instrument will probably be more economical and long lasting than RIRS. There are important differences in the training of these procedures. While RIRS needs a structured training program with virtual reality or high fidelity non-virtual reality models, microperc can be more easily mastered by any Urologist who is trained in standard PCNL.

\section{CONCLUSIONS}

Microperc is an emerging minimally invasive PCNL technique. It is currently used to manage single renal calculus or multiple renal calculi, which can be accessed with a single puncture and cumulative diameter of less than $1.5 \mathrm{~cm}$ in diameter. Though it can be used in intermediate sized calculi, it is preferable to use microperc so that the fragments can be removed from pelvicalyceal system. It can be safely used in the pediatric age group, ectopic kidneys, chronic kidney disease and bladder calculi the high stone clearance rate and lower complication rate associated with microperc make it a viable alternative to RIRS. Moreover, it is associated with lower risk of ureteric trauma and lower need for prolonged post-operative ureteric stenting.

Prospective randomized studies comparing microperc with SWL will help to establish its role relative to $S W L$.

\section{REFERENCES}

1. Albala DM, Assimos DG, Clayman RV, Denstedt JD, Grasso M, Gutierrez-Aceves J, Kahn RI, Leveillee RJ, Lingeman JE, Macaluso JN, Munch LC. Lower pole I: a prospective randomized trial of extracorporeal shock wave lithotripsy and percutaneous nephrostolithotomy for lower pole nephrolithiasis-initial results. The Journal of urology. 2001 Dec;166(6):2072-80.

2. Rosette JD, Assimos D, Desai M, Gutierrez J, Lingeman J, Scarpa R, Tefekli A. The clinical research office of the endourological society percutaneous nephrolithotomy global study: indications, complications, and outcomes in 5803 patients. Journal of endourology. 2011 Jan 1;25(1):11-7.

3. Elbahnasy AM, Shalhav Al, Hoenig DM, Elashry OM, Smith DS, Mcdougall EM, Clayman RV. Lower caliceal stone clearance after shock wave lithotripsy or ureteroscopy: the impact of lower pole radiographic anatomy. The Journal of urology. 1998 Mar;159(3):676-82.

4. Pearle MS, Lingeman JE, Leveillee R, Kuo R, Preminger GM, Nadler RB, Macaluso J, Monga M, Kumar U, Dushinski J, Albala DM. Prospective, randomized trial comparing shock wave lithotripsy and ureteroscopy for lower pole caliceal calculi 1 $\mathrm{cm}$ or less. The Journal of urology. 2005 Jun;173(6):2005-9.

5. Ozturk U, Sener NC, Goktug HG, Nalbant I, Gucuk A, Imamoglu MA. Comparison of percutaneous nephrolithotomy, shock wave lithotripsy, and retrograde intrarenal surgery for lower pole renal calculi 10-20 $\mathrm{mm}$. Urologia internationalis. 2013;91(3):345-9.

6. Schoenthaler M, Wilhelm K, Hein S, Adams F, Schlager D, Wetterauer U, Hawizy A, Bourdoumis A, Desai J, Miernik A. Ultra-mini PCNL versus flexible ureteroscopy: a matched analysis of treatment costs (endoscopes and disposables) in patients with renal stones 10-20 mm. World journal of urology. 2015 Oct 1;33(10):1601-5.

7. Abdelhafez MF, Bedke J, Amend B, ElGanainy E, Aboulella H, Elakkad M, Nagele U, Stenzl A, Schilling D. Minimally invasive percutaneous nephrolitholapaxy (PCNL) as an effective and safe procedure for large renal stones. BJU international. 2012 Dec;110(11c):E1022-6.

8. Desai J, Solanki R. Ultra-mini percutaneous nephrolithotomy (UMP): one more armamentarium. BJU international. 2013 Nov;112(7):1046-9.

9. Desai MR, Sharma R, Mishra S, Sabnis RB, Stief C, Bader M. Single-step percutaneous nephrolithotomy (microperc): the initial clinical report. The Journal of urology. 2011 Jul $1 ; 186(1): 140-5$.

10. Jackman SV, Hedican SP, Peters CA, Docimo SG. Percutaneous nephrolithotomy in infants and preschool age children: experience with a new technique. Urology. 1998 Oct 1;52(4):697-701.

11. Helal M, Black T, Lockhart J, Figueroa TE. The Hickman peel-away sheath: alternative for pediatric percutaneous nephrolithotomy. Journal of endourology. 1997 Jun;11(3):171-2. 
12. Desai M. Ultrasonography-guided punctures-with and without puncture guide. J Endourol. 2009;23:1641-3.

13. Penbegul N, Bodakci MN, Hatipoglu NK, Sancaktutar AA, Atar M, Cakmakci S, Yildirim K. Microsheath for microperc: 14-gauge angiocath. Journal of endourology. $2013 \mathrm{Jul}$ 1;27(7):835-9.

14. Piskin MM, Guven S, Kilinc M, Arslan M, Goger E, Ozturk A. Preliminary, favorable experience with microperc in kidney and bladder stones. Journal of endourology. 2012 Nov 1;26(11):14437.

15. Tepeler A, Armagan A, Sancaktutar AA, Silay MS, Penbegul N, Akman T, Hatipoglu NK, Ersoz C, Erdem MR, Akcay M. The role of microperc in the treatment of symptomatic lower pole renal calculi. Journal of endourology. 2013 Jan 1;27(1):13-8.

16. Armagan A, Tepeler A, Silay MS, Ersoz C, Akcay M, Akman T, Erdem MR, Onol SY. Micropercutaneous nephrolithotomy in the treatment of moderate-size renal calculi. Journal of endourology. 2013 Feb 1;27(2):177-81.

17. Sofer M, Watterson JD, Wollin TA, Nott L, Razvi H, Denstedt JD. Holmium: YAG laser lithotripsy for upper urinary tract calculi in 598 patients. The Journal of urology. 2002 Jan;167(1):31-4.

18. Sabnis RB, Jagtap J, Mishra S, Desai M. Treating renal calculi $1-2 \mathrm{~cm}$ in diameter with minipercutaneous or retrograde intrarenal surgery: a prospective comparative study. BJU international. 2012 Oct;110(8b):E346-9.

19. Knoll T, Jessen JP, Honeck P, Wendt-Nordahl G. Flexible ureterorenoscopy versus miniaturized PNL for solitary renal calculi of 10-30 mm size. World journal of urology. 2011 Dec 1;29(6):755-9.

20. Traxer O, Thomas A. Prospective evaluation and classification of ureteral wall injuries resulting from insertion of a ureteral access sheath during retrograde intrarenal surgery. The Journal of urology. 2013 Feb 1;189(2):580-4.

21. Kaynar M, Sümer A, Şalvarcı A, Tekinarslan E, Cenker A, Istanbulluoğlu MO. Micropercutaneous nephrolithotomy (microperc) in a two-year-old with the 'all-seeing needle'. Urologia internationalis. 2013;91(2):239-41.

22. Unsal A, Resorlu B. Retrograde intrarenal surgery in infants and preschool-age children. J Pediatr Surg. 2011;46:2195-9.
23. Kim SS, Kolon TF, Canter D, White M, Casale P. Pediatric flexible ureteroscopic lithotripsy: The children's hospital of Philadelphia experience. J Urol. 2008;180:2616-9.

24. Ganesamoni R, Mishra S, Kumar A, Ganpule A, Vyas J, Ganatra P, Sabnis RB, Desai MR. Role of active mentoring during flexible ureteroscopy training. Journal of endourology. 2012 Oct 1;26(10):1346-9.

25. Mishra S, Sabnis RB, Doshi A, Desai MR. First multicentric data on feasibility of microperc for non bulky renal urolithiasis. Injournal of endourology. 2012; sep 1 26, 194-a194. 140 huguenot street, 3RD FL, NEW ROCHELLE, NY 10801 USA: MARY ANN LIEBERT INC.

26. El-Nahas AR, Ibrahim HM, Youssef RF, Sheir KZ. Flexible ureterorenoscopy versus extracorporeal shock wave lithotripsy for treatment of lower pole stones of 10-20 mm. BJU Int. 2012;110:898-902.

27. Ansari MS, Gupta NP, Hemal AK, Dogra PN, Seth A, Aron M. Spectrum of stone composition: Structural analysis of 1050 upper urinary tract calculi from northern India. Int J Urol. 2005;12:126.

28. Srisubat A, Potisat S, Lojanapiwat B, Setthawong V, Laopaiboon M. Extracorporeal shock wave lithotripsy (ESWL) versus percutaneous nephrolithotomy (PCNL) or retrograde intrarenal surgery (RIRS) for kidney stones. Cochrane Database Syst Rev. 2009;4:CD007044.

29. Ansari MS, Gupta NP, Seth A, Hemal AK, Dogra PN, Singh TP. Stone fragility: Its therapeutic implications in shock wave lithotripsy of upper urinary tract stones. Int Urol Nephrol. 2003;35:387-92.

30. Aboumarzouk OM, Kata SG, Keeley FX, McClinton S, Nabi G. Extracorporeal shock wave lithotripsy (ESWL) versus ureteroscopic management for ureteric calculi. Cochrane Database Syst Rev. 2012;5:CD006029.

31. Tepeler A, Silay MS, Armagan A, Basibuyuk I, Akman T, Akcay M, Onol SY. Laparoscopicassisted "microperc" of a stone in a pelvic kidney of a 3-year-old girl. Journal of Laparoendoscopic \& Advanced Surgical Techniques. 2013 Feb $1 ; 23(2): 174-6$. 